\title{
Maternal-Fetal Prognosis of Eclampsia at the Second Reference Hospital in the Urban Commune of Segou in Mali
}

\author{
Tidiani Traoré1 ${ }^{*}$, Cheickna Sylla² ${ }^{2}$ Kassoum Sidibé1, Babou Traoré1, Sylvain Guindo1, \\ Adama Coulibaly ${ }^{1}$, Seydina A. Beye ${ }^{1}$, Seydou Z. Dao ${ }^{3}$, Famakan Kané4, Youssouf Traoré5, \\ Ibrahima Téguété ${ }^{5}$, Moustaphe Touré 6
}

\begin{abstract}
${ }^{1}$ Department of Gynecology and Obstetrics, NianankoroFomba Hospital, Ségou, Mali
${ }^{2}$ Department of Gynecology and Obstetrics, Reference Health Centre in Koutiala, Sikasso, Mali

${ }^{3}$ Department of Gynecology and Obstetrics, Reference Health Centre of Commune II, Bamako, Mali

${ }^{4}$ Department of Gynecology and Obstetrics, Reference Health Centre in Bla, Ségou, Mali

${ }^{5}$ Department of Gynecology and Obstetrics, Gabriel TOURE University Hospital Center, Bamako, Mali

${ }^{6}$ Department of Gynecology and Obstetrics, University Hospital Center of the Mali Hospital, Bamako, Mali

Email: ${ }^{\star}$ tidiniako@gmail.com
\end{abstract}

How to cite this paper: Traoré, T., Sylla, C., Sidibé, K., Traoré, B., Guindo, S., Coulibaly, A., Beye, S.A., Dao, S.Z., Kané, F., Traoré, Y., Téguété, I. and Touré, M. (2020) Maternal-Fetal Prognosis of Eclampsia at the Second Reference Hospital in the Urban Commune of Segou in Mali. Open Journal of Obstetrics and Gynecology, 10, 1414-1429.

https://doi.org/10.4236/ojog.2020.10100130

Received: September 7, 2020

Accepted: October 17, 2020

Published: October 20, 2020

Copyright $\odot 2020$ by author(s) and Scientific Research Publishing Inc. This work is licensed under the Creative Commons Attribution International License (CC BY 4.0).

http://creativecommons.org/licenses/by/4.0/

\begin{abstract}
Aim: To describe the epidemiological, therapeutic and prognostic aspects of eclampsia at the second reference hospital in the urban commune of Ségou in Mali. Patient and Methods: This was a descriptive, cross-sectional, analytical, retrospective and prospective study based on a comprehensive de-engineering. It covered a 3-year period from January 1, 2010 to December 31, 2012 and involved 176 cases. Results: The incidence of eclampsia during the study period was $2.9 \%$. Classically, it occurred in $74.4 \%$ in young primigeste, in $73.9 \%$ in the $3^{\text {rd }}$ trimester of pregnancy and $26.1 \%$ of cases during postpartum. We recorded maternal complications such as retro-placental hematoma, acute kidney failure and delivery hemorrhage. The case fatality rate was $2.3 \%$ or 4 cases of maternal death. At the fetal level, there was $29.5 \%$ prematurity, $31.8 \%$ neonatal suffering, $11.4 \%$ hypotrophy, $11.9 \%$ in utero fetal death and $7.4 \%$ early neonatal death. Conclusion: The maternal-fetal prognosis remains reserved despite the progress made in the management of eclampsia in our services.
\end{abstract}

\section{Keywords}

Pronostic, Maternal, Fetal, Eclampsia, Unsealed Pregnancy

\section{Introduction}

A paroxysmal complication of pre-eclampsia, eclampsia is a serious obstetric 
situation responsible for significant maternal and perinatal mortality and morbidity (6\% - 10\%) according to FAYE A. [1] in his study of eclampsia at the University Hospital of Libreville published in the French journal of obstetric gynecology. They are more common in developing countries than in developed countries.

They contribute to worsening maternal mortality and morbidity in developing countries. As a result, the rate of eclampsia is an indicator of the level of socio-health organization of a country, a region.

What are the epidemiological, therapeutic and prognostic specificities of eclampsia in a context lack of qualified personnel, difficult geographical accessibility and the reference and counter-reference system with failures at the second reference hospital in Ségou, Mali?

\section{Objectives}

Objective: To describe the epidemiological, therapeutic and prognostic aspects of eclampsia at the second reference hospital in the urban commune of Ségou in Mali.

\section{Patients and Methods}

This was a cross-sectional, analytical descriptive study with retrospective data collection (January 2010 to December 2012) or a 3-year study period in the obstetric gynecology department of the second-reference hospital in Ségou, Mali. Human resources available: For the obstetric gynecology department, we have two (2) Specialists in Obstetric Gynecology; two (2) General Practitioners; eight (08) Midwives; Five (5) Obstetrician nurses. For the resuscitation anesthesia department, we have a resuscitator anaesthetist, four nurses. For the paediatric ward, we have three (03) doctors, five (05) nurses. The study population consisted of pregnant women, parturients and birth attendants admitted to the ward. The sampling was exhaustive. The criteria for inclusion were: patients who have a tonic-clonic attack associated with systolic hypertension (HTA) of $140 \mathrm{mmHg}$ or/or higher diastolic blood pressure or equal to $90 \mathrm{mmHg}$ (HTA-140/90 $\mathrm{mmHg}$ ) associated with a positive two-cross urinary strip (significant proteinuria $-0.30 \mathrm{~g} / 24 \mathrm{H}$ ). Patients whose records were not available, as well as those who had seizures during pregnancy not associated with high blood pressure, were excluded: convulsive seizures related to pernicious bouts of malaria confirmed by thick gout, epileptic seizures with the notion of history-based seizures, and ongoing anti-epileptic treatment. The data was collected using a previously tested fact sheet. The sources of data collection were: medical records, admission, delivery, and operational reporting records. The reference sheets/evacuations were used to collect the general information of the evacuated patients. The variables studied were: epidemiological characteristics (age, parity, number of antenatal consultations, risk factors, patient origin), therapeutic aspects (delivery pathway, resuscitation, blood transfusion) and prognostic (the morbi maternal-fetal mortality). The limits: the lack of financial resources and the inadequacy of the tech- 
nical platform to carry out certain biological examinations, the incompleteness of certain files of the retrospective period were limiting factor. The data collected were processed and analyzed using the 2000 EPI info, EXCEL and WORD 2007 logitials. Quantitative variables were expressed on average and standard deviation, qualitative variables as a percentage.

\section{Results}

After counting, 176 files met the inclusion criteria that served as work materials. It was these 176 files that were used as materials

Epidemiological characteristics: During the study period we recorded 176 cases of eclampsia out of the $\mathbf{5 9 7 6}$ patients admitted during the gravido-postpartum period, representing a frequency of $2.9 \%$. The average age of the patients was 20.65 years with extremes of 14 and 44 years. The $14-19$ age group was the most affected with a frequency of $60.2 \%$. In our series $81.8 \%$ of patients were out of school and $13.6 \%$ had a primary level. These are patients who were most often unaware of the importance of antenatal consultations whose pregnancies were not followed or poorly followed. $61.9 \%$ of patients had not performed any antenatal consultations.

Table 1 summarizes the epidemiological characteristics of patients.

Table 1. Epidemiological characteristics of patients admitted for eclampsia at the second referral hospital in Ségou, Mali from 2010 to 2012.

\begin{tabular}{ccc}
\hline Characteristics & Effective & Percentage \\
\hline Age in year & & \\
$14-19$ years old & 106 & $60.2 \%$ \\
20 - 34 years old & 62 & $35.2 \%$ \\
35 - 44 years old & 8 & $4.5 \%$ \\
Parity & & \\
Nullipare & 84 & 47.7 \\
Primipare (parity 1) & 53 & 30.1 \\
Paucipare (parity 2 to 3) & 19 & 10.8 \\
Multipare (parity 4 to 5) & 13 & 7.4 \\
Large multipare (parity above 5) & 7 & 4 \\
Educational level & & \\
Out of school & 144 & 81.8 \\
Primary level & 24 & 13.6 \\
Secondary school & 8 & 4.6 \\
Profession & 138 & 3.4 \\
Housewife & 31 & 0.6 \\
Student-student & 6.4 \\
Housekeeper & 13.6 \\
Hairdresser & &
\end{tabular}


These were patients evacuated in $66.4 \%$ of cases and they came from health facilities located within a $150 \mathrm{~km}$ radius.

Direct admissions accounted for $33.6 \%$ of cases. Table 2 shows the distribution of eclamps according to the method of admission.

Clinical aspects: The eclampsia attack occurred in anate, per or post partum with varying tension figures having more or an impact on the condition of the fetus as shown in Table 3.

\subsection{Therapeutic and Prognostic Aspects}

In our study $54.5 \%$ of patients had given birth by caesarean section. The delay between the crisis and childbirth was more than 5 hours in $63.1 \%$. Medical treatment has been instituted in all of our patients. This treatment associated: antihypertensives whose most used was Nicardipine $10 \mathrm{ml}$ in $88.6 \%$ of cases, anti-convulsives whose most used was magnesium sulphate $\left(\mathrm{MgSO}_{4}\right)$ in $90.9 \%$ of cases, oxygen therapy in $18.2 \%$ of cases.

As our service does not have a resuscitation unit, $43.7 \%$ of our patients were transferred to resuscitation and had an average stay of 2.71 days. The average length of hospitalization was 4.52 days (Table 4 ).

Table 2. Distribution of patients admitted for eclampsia at Fousseini Dao Hospital in Ségou, Mali from 2010 to 2012, depending on the method of admission.

\begin{tabular}{ccc}
\hline From & Effective & Frequency (\%) \\
\hline Evacuation & 117 & 66.4 \\
Direct admission & 59 & 33.6 \\
\hline
\end{tabular}

Table 3. Breakdown of eclamptics based on voltage factors, fetal condition and timing of the seizure.

\begin{tabular}{ccc}
\hline TA Systolic in mmHg & Staff & Frequency (\%) \\
\hline 150 & 93 & 52.8 \\
$140-150$ & 73 & 41.5 \\
140 & 10 & 5.7 \\
\hline TA Diastolic in mmHg & 107 & 60.8 \\
\hline $90-100$ & 63 & 35.8 \\
100 & 6 & 3.4 \\
90 & & 86.1 \\
BDCF & 112 & 13.9 \\
Present & 18 & \\
Absent & & 41.5 \\
\hline The timing of the crisis & 73 & 32.4 \\
Per-partum & 57 & 26.1 \\
Anté-partum & 46 & \\
Postpartum & & \\
\hline
\end{tabular}


Table 4. Distribution of patients by delivery pathway, medical treatment received, transfer to resuscitation and length of hospital stay at the second-reference hospital in Ségou, Mali from 2010 to 2012.

\begin{tabular}{|c|c|c|}
\hline Delivery lane & Staff & Frequency (\%) \\
\hline Caesarean section & 96 & 54.5 \\
\hline Low track & 80 & 45.5 \\
\hline \multicolumn{3}{|l|}{$\begin{array}{l}\text { Time between the onset of the crisis } \\
\text { and childbirth }\end{array}$} \\
\hline 5 hours & 82 & 63.1 \\
\hline $3-5$ hours & 38 & 29.2 \\
\hline $1-2$ hours & 8 & 6.2 \\
\hline 1 hour & 2 & 1.5 \\
\hline \multicolumn{3}{|l|}{ Treatment received before admission } \\
\hline No treatment & 92 & 52.3 \\
\hline Antihypertensive and anticonvulsant & 37 & 21.0 \\
\hline Anticonvulsant & 28 & 15.9 \\
\hline Antihypertensive & 19 & 10.8 \\
\hline \multicolumn{3}{|l|}{ Anti-hypertensive } \\
\hline Nicardipine & 156 & 88.6 \\
\hline Nifedipine & 9 & 5.1 \\
\hline Methyldopa & 7 & 4.0 \\
\hline Furosemide & 4 & 2.3 \\
\hline \multicolumn{3}{|l|}{ Transfer to resuscitation } \\
\hline Not & 99 & 56.3 \\
\hline Yes & 77 & 43.7 \\
\hline \multicolumn{3}{|l|}{ Length of stay in resuscitation in days } \\
\hline $1-3$ & 64 & 83.1 \\
\hline $4-7$ & 11 & 14.3 \\
\hline 8 & 2 & 2.6 \\
\hline \multicolumn{3}{|l|}{ Length of hospitalization in days } \\
\hline 3 & 4 & 2.2 \\
\hline $3-7$ & 155 & 88.1 \\
\hline $8-15$ & 17 & 9.7 \\
\hline
\end{tabular}

\subsection{Prognosis}

Maternal complications accounted for $8.5 \%$ of cases. These maternal and fetal complications are listed in Table 5.

Infectious complications (endometritis and parietal suppuration) were the most common maternal complications with $53.4 \%$ of cases. The other complications were represented acute kidney failure with $20 \%$ of cases, retro-placental 
hematoma in $13.3 \%$ of cases and delivery haemorrhage in $13.3 \%$. We recorded 4 cases of maternal deaths (2.3\%) 50\% following a state of eclamptic disease, $25 \%$ following acute kidney failure and $25 \%$ following acute edema of the lung. Fetal complications were dominated by prematurity (29.5\%) neonatal suffering (13.6\%), hypotrophy (11.4\%) and fetal death (14.7\%).

Eclampsia is a pathology responsible for maternal and fetal complications that are sometimes serious. In our study, we recorded $8.5 \%$ of maternal complications. Referring to the distribution of cases by type of complications, we find that infectious complications (endometritis and parietal suppuration) are most often related to delivery conditions than to eclampsia itself. On the other hand acute kidney failure appears in 20\%; retro-placental hematoma in $13.3 \%$ and hemorrhage of delivery in $13.3 \%$. Eclampsia was lethal in $2.3 \%$ of cases. These deaths occurred in varying circumstances such as: $50 \%$ eclamptic condition; acute kidney failure in $25 \%$; acute lung edema in $25 \%$ of cases.

Table 5. Patient distribution based on maternal-fetal complications.

\begin{tabular}{|c|c|c|}
\hline Complications & Staff & Frequency (\%) \\
\hline Infection & 8 & 53.4 \\
\hline Ira & 3 & 20 \\
\hline Hemorrhage of deliverance & 2 & 13.3 \\
\hline Hrp & 2 & 13.3 \\
\hline \multicolumn{3}{|l|}{ Apgar score } \\
\hline 0 & 18 & 13.6 \\
\hline $1-3$ & 6 & 4.6 \\
\hline $4-6$ & 12 & 9.1 \\
\hline 7 & 96 & 72.7 \\
\hline \multicolumn{3}{|l|}{ Newborn status } \\
\hline Eutrophic & 78 & 59.1 \\
\hline Premature & 39 & 29.5 \\
\hline ! Hypotrophic & 15 & 11.4 \\
\hline \multicolumn{3}{|l|}{ Revived } \\
\hline Not & 114 & 86.4 \\
\hline Yes & 18 & 13.6 \\
\hline \multicolumn{3}{|l|}{ Life-threatening infant } \\
\hline Died after resuscitation & 13 & 7.4 \\
\hline Fresh stillborn & 17 & 9.6 \\
\hline Stillborn macerated & 4 & 2.3 \\
\hline Living & 142 & 80.7 \\
\hline \multicolumn{3}{|l|}{ Maternal prognosis } \\
\hline Living & 172 & 97.7 \\
\hline Deceased & 4 & 2.3 \\
\hline
\end{tabular}


Eclampsia is often associated with morbid fetal complications. These are dominated by prematurity (29.5\%) hypotrophy (11.4\%).

Fetal death in utero was noted in $13.7 \%$ of living infants were resuscitated and referred to the paediatric ward for neonatal suffering. The stillbirth rate was $11.9 \%$.

Table 6, Table 7 and Table 8 show us the search for a statistical relationship between certain study variables.

Table 6. Patient breakdown by the relationship between maternal Glasgow and Apgar score at the second reference hospital in Ségou, Mali from 2010 to 2012.

\begin{tabular}{cccccc}
\hline \multirow{5}{*}{ Glasgow score } & \multicolumn{5}{c}{ Apgar score } \\
\cline { 2 - 6 } & $\mathbf{0}$ & $\mathbf{1}-\mathbf{3}$ & $\mathbf{4 - 6}$ & $\mathbf{7}$ & Total \\
\hline $\mathbf{1 3 - 1 5}$ & $2(11.1)$ & $0(0)$ & $2(16.6)$ & $8(8.3)$ & $12(9.1)$ \\
$\mathbf{9}-\mathbf{1 2}$ & $13(72.2)$ & $6(100)$ & $5(41.7)$ & $73(76)$ & $97(73.5)$ \\
$\mathbf{3}-\mathbf{8}$ & $3(16.7)$ & $0(0)$ & $5(41.7)$ & $15(15.7)$ & $23(17.4)$ \\
Total & $18(100)$ & $6(100)$ & $12(100)$ & $96(100)$ & $132(100)$ \\
\hline
\end{tabular}

Khi2-9.0382; ddl-6 and p-0.1714.

Table 7. Distribution of patients by the relationship between the period of onset of the crisis and the fetal prognosis at the second reference hospital in Ségou, Mali from 2010 to 2012 .

\begin{tabular}{cccccc}
\hline & \multicolumn{4}{c}{ Vital Newborn Prognosis } \\
\cline { 2 - 6 } The crisis & Deceased & $\begin{array}{c}\text { Stillborn } \\
\text { Fresh }\end{array}$ & $\begin{array}{c}\text { Stillborn } \\
\text { macerated }\end{array}$ & Living & Total \\
\hline Anté-partum & $10(76.9)$ & $11(64.7)$ & $2(50)$ & $50(35.2)$ & $73(41.5)$ \\
Per-partum & $3(23.1)$ & $5(29.4)$ & $0(0)$ & $49(34.5)$ & $57(32.4)$ \\
Postpartum & $0(0)$ & $1(5.9)$ & $2(50)$ & $43(30.3)$ & $46(26.1)$ \\
Total & $13(100)$ & $17(100)$ & $4(100)$ & $142(100)$ & $176(100)$ \\
\hline
\end{tabular}

Khi2-17, 3217; ddl-6 and p-0.0082.

Table 8. Patient breakdown by the relationship between the birth route and the Glasgow score at the second reference hospital in Ségou, Mali from 2010 to 2012.

\begin{tabular}{ccccc}
\hline \multirow{2}{*}{ Delivery lane } & \multicolumn{4}{c}{ Glasgow score } \\
\cline { 2 - 5 } & $\mathbf{1 3 - 1 5}$ & $\mathbf{3 - 8}$ & $\mathbf{9 - 1 2}$ & Total \\
\hline Caesarean section & $3(15.8)$ & $10(31.3)$ & $83(66.4)$ & $96(54.5)$ \\
Low track & $16(84.2)$ & $22(68.7)$ & $42(33.6)$ & $80(45.5)$ \\
Total & $19(100)$ & $32(100)$ & $125(100)$ & $176(100)$ \\
\hline
\end{tabular}

Khi2-25.60, ddl-2 and p-0.000. 


\section{Discussion}

\subsection{The Frequency}

The lack of financial resources and the inadequacy of the technical platform to carry out certain biological examinations, the incompleteness of certain files of the retrospective period were limiting factor in the follow-up and management of patients. Despite these limitations, this study has allowed us to obtain results comparable to other studies.

The frequency of eclampsia during the posted gravity period was $2.9 \%$. This frequency varies according to the authors this is how ours was superior to those reported by AHMADOU $\mathrm{H}$. with $0.78 \%$ of cases [2], CISSE CT. and Al with $0.8 \%$ of cases [3], PAMBOU O. and $\mathrm{Al}$ with $0.32 \%$ of cases [4], DEMBELE N F. with $1.13 \%$ of cases [5].

Our frequency could be explained by the free caesarean section in Mali but also by the fact that our hospital has a resuscitation service thus receiving references from all health facilities in the region and some neighbouring regions.

Eclampsia is rare in Europe, with an incidence of 1.5 to 3 per 10,000 pregnancies [6] [7].

The dysfunction of the health system, the poor organization of health care that results in the absence or irregularity in prenatal follow-up, the delay in management could explain this difference in frequency between developing and developed countries.

\subsection{Socio-Demographic Characteristics}

The average age was 20.65 years with a predominance of the 14 to 19 age group. The same trend has been reported by Keita $M$ and Col. with average age $20-4 \pm$ years and predominance of the 15 - 19 age group [8].

Our teenage girls' rate was $60.2 \%$ of cases. Our result is higher than other studies carried out in Mali with $48 \%$ respectively; $48.60 \%$ and $50.8 \%$ [5] [6] [7].

Most authors agree that adolescence is a factor in eclampsia due to their physiological immaturity and inexperience for proper prenatal follow-up.

According to some studies eclampsia is a condition of a young priparous woman under 25 years of age or of the multipare over 35 years of age [8]. We noted a predominance of primigeste (74.4\%). This predominance of young primipares is reported by M. D. Beye et al. [9] (64.2\%), Cissé CT et al. [10] (74.4\%).

We have $77.3 \%$ housewives versus $22.7 \%$ singles. Our singles rate is lower than that of AHMADOU H. [2] and superior to that of HAMDA S. [10] with reported $24.74 \%$ and $20.60 \%$ of cases respectively. Single women in our country are most often without financial support inciting them to risky unwanted pregnancy behaviours that the perpetrator is not always identified

Financial management of single pregnancies is a problem most often. Sometimes the perpetrator of the pregnancy is not known. However, even if the latter is known, there is a refusal to recognize this paternity of the pregnancy. We think like MERGER R. [8] that young primigestes are most often exposed to this 
pathology. On the one hand, it appears that the ages corresponding to the peak of eclampsia are those of the optimum procreation period. On the other hand, through the age there are socio-cultural realities. In fact, this difference hides the same reality, which is the low purchasing and decision-making power of the women concerned. In our series $81.8 \%$ of them were out of school and $13.6 \%$ had a primary level. These were patients who were most often unaware of the importance of antenatal consultations whose pregnancies were not followed or poorly followed. Our result is superimposed on those of KONATE S. [11] and DIARRA I. [6] who rated $72.56 \%$ and $74 \%$ respectively. They had not performed any antenatal consultations in $61.9 \%$. However, $38.1 \%$ of them had done between 1 and 6 antenatal consultations during their pregnancy. The realities on the ground are many. It was noted that for those who had performed 1 to 6 antenatal consultations and who presented eclampsia, they reflected the community realities concerning the decision-making power of women to visit health training, including the lack of attendance at these facilities and the lack of qualified staff in most of our health facilities, sometimes of poor quality of pregnancy monitoring. Some patients had a pathological history (1.1\% eclampsia; $2.9 \%$ high blood pressure). Only good quality antenatal consultations can be detected and adequately managed for severe forms of pre-eclampsia, and are one way to reduce the frequency of eclampsia and improve maternal-fetal prognosis.

The quality of the reference/evacuation in a country can influence the frequency of eclampsia. Thus, $66.4 \%$ of our patients came from health facilities within a $150 \mathrm{~km}$ radius compared to $33.6 \%$ of direct admissions. Our results are similar to those of DEMBELE N.F. [5] which yielded $69 \%$ medical evacuation for eclampsia and $31 \%$ of direct admissions.

In our series, illiterates were the most affected with $81.8 \%$. Our frequency is higher than that of DIARRA I. [6] and lower than FOFANA B. [12] who reported an illiteracy rate of $74 \%$ and $85 \%$ respectively. This shows us a low rate of school enrolment within the country. In the organization of our societies, women most often have modest or unfavourable socio-economic conditions and are unaware of the importance of antenatal consultations.

\subsection{Clinical Aspects}

High blood pressure is the first warning sign in this context of eclampsia. It appears to be the predictor of a poor maternal-fetal prognosis. In our study, systolic HTA was found in $94.3 \%$ with extremes of 140 and $240 \mathrm{mmHg}$. It was severe in $52.8 \%$. As for the diastolic HTA that was most often associated with this systolic HTA was found in $96.6 \%$ with extremes of 90 and $140 \mathrm{mmHg}$ and it was severe in $35.8 \%$. Our result is higher than that of DIAKITE M. [13] which reported $82.6 \%$ systolic HTA between 130 and $160 \mathrm{mmHg}$ and severe in $50.9 \%$ of cases. And these patients had in $85.6 \%$ diastolic HTA which was between 90 and $100 \mathrm{mmHg}$ and severe in $41.8 \%$. Changes in fetal heart rate are related to maternal hemodynamic disorders that result in either acute fetal suffering or fetal 
death. Fetal death was diagnosed at admission in $13.9 \%$. When these fetuses were alive, they had fetal suffering with abnormal fetal heart noises in $14.6 \%$ (5.4\% fetal bradycardia and $9.2 \%$ fetal tachycardia). Our result is lower than that of DIARRA I. [6] which yielded $26 \%$ at admission and $60 \%$ pathological (18\% fetal bradycardia and $42 \%$ fetal tachycardia).

The alteration of the state of consciousness was frequently noted in our patients ranging from simple obnubilation to deep coma. This alteration of the state of consciousness was related to the number of seizures.

More than half of our patients had their long-term pregnancy as in DIARRA I. [6] (54\%). This trend is also observed in CISSE CT. [3] which finds a high frequency of eclampsia on pregnancies-37 SA. Postpartum eclampsia accounted for only $26.1 \%$ in our series, while in 20 th and per-partum, it accounted for $32.4 \%$ and $41.5 \%$ respectively. Trend observed in DEMBELE N F. [5] which pays $(20.7 \%)$ postpartum eclampsia. In the Moroccan and Tunisian series, eclampsia in the preparationtum is the most common. Indeed at the Ibn Rochd University Hospital in Casablanca, Morocco, MIGUIL M. et al. [14] reported $79 \%$ of cases of eclampsia before work, $4 \%$ during work and $17 \%$ after work. In Tunisia Ferchiou M. et al. [15] found 56.9\% in preparationtum; 32.5\% in per-partum and $10.6 \%$ in postpartum. Indeed, the remoteness of our health facilities makes the delay longer between the admission of patients to our ward and the appearance of the first seizures that helped to trigger the work. This may explain this difference with the other authors.

\subsection{Statistical Analyses between Variables}

The Glasgow score calculated to assess a patient's level of consciousness may be related to the Apgar of the newborn, however our study did not find a statistical link (Table 6) [Khi2-9.0382; ddl-6 and p-0.1714].

The appearance of the first convulsive seizures that contribute to triggering labour, the poor fetal-maternal exchanges caused by pre-eclampsia with its consequences of intrauterine growth retardation and stillbirth explained tell us more about a significant statistical link between fetal prognosis and the period of occurrence of seizures as shown in Table 7 [Khi2-17,3217; ddl-6 and P-0.0082].

The coma that takes place after several seizures makes vaginal delivery difficult. So many authors opt for caesarean section. This close relationship between the birthing route and the Glasgow score was reported by our series with a Khi2-25.60, ddl-2 and p-0.0000 (Table 8).

\subsection{Support}

Indeed, the crisis often triggers labour in this context of remoteness from our health facilities with the consequences of deliveries before arrival at the centre.

In our study $54.5 \%$ of our patients were caesarean. This result is lower than that of DIAKITE M. [13] who had a caesarean section rate of $85.1 \%$. In the MOMA survey conducted in West Africa cited by DUMONT A. and Col [16], 
the rate of caesarean section found in cases of eclampsia is $87 \%$ of cases, which is higher than our result. These are most often patients admitted in latency with unstable tension figures most often associated with acute fetal suffering.

The prognosis reflects the quality of prevention and care at all levels of care. For this management, we have instituted medical treatment in all our patients. This treatment has combined several molecules. These were anti-hypertensives whose most used was nicardipine $10 \mathrm{ml}$ in $88.6 \%$; anti-convulsants, the most commonly used of which was Magnesium Sulfate $\left(\mathrm{MgSO}_{4}\right)$ in $90.9 \%$; oxygen therapy in $18.2 \%$ in crisis intervals and vascular filling of all our patients. As our service does not have a resuscitation unit, $43.7 \%$ of our patients were transferred to resuscitation and all returned to the ward after an average stay of 2.71 days. The average length of hospitalization was 4.52 days.

\subsection{Prognosis}

Eclampsia is a pathology responsible for maternal and fetal complications that are sometimes serious. In our study, we recorded $8.5 \%$ of maternal complications. Referring to the distribution of cases by type of complications, we find that infectious complications (endometritis and parietal suppuration) are most often related to delivery conditions than to eclampsia itself. On the other hand acute kidney failure appears in 20\%; retro-placental hematoma in $13.3 \%$ and hemorrhage of delivery in $13.3 \%$. Eclampsia was lethal in 4 cases or $2.3 \%$. These deaths occurred in varying circumstances such as: $50 \%$ eclamptic condition; acute kidney failure in $25 \%$; acute lung edema in $25 \%$ of cases.

Lethality rates higher than ours are reported by the following authors: DIAKITE M. [13] had 6.2\% maternal deaths; KONATE S. [11] had 4.26\% maternal deaths; DIARRA I. [6] had 12\% maternal deaths; TRAORE et al. [17] had $18.8 \%$ maternal deaths. By comparing our result with those of the above-mentioned authors, we can say that the frequency of eclampsia was higher in our study and the maternal prognosis is less severe. This could be explained by the current improvement in case management with free caesarean section and the use of magnesium sulphate. The difference in the quality of care between developed and developing countries remains relevant and explains this death rate reported by the French series [18] which is $2.2 \%$ lower than ours.

Eclampsia is often associated with morbid fetal complications. These are dominated by prematurity (29.5\%) hypotrophy (11.4\%). Most African authors [18] [19] [20] in their series reported prematurity rates around $50 \%$ and SANOGO A. [21] recorded $11.7 \%$ prematurity.

Eclampsia due to repeated seizures, tension figures, and utero-placental ischemia is responsible for fetal death in utero. $13.7 \%$ of live infants were resuscitated and referred to the paediatric ward for neonatal suffering. We see a marked decrease in the stillbirth rate of $11.9 \%$ for our series of $24 \%$ and $17 \%$ for studies conducted a few years earlier [5] [6] in the same department. This improvement in fetal prognosis may be due to the significant changes that have 
been made in the organization of working conditions in recent years (free caesarean section, monitoring of labour by partogram and free magnesium sulphate).

\section{Conclusion}

The maternal-fetal prognosis remains reserved despite the progress made in the management of eclampsia in our services.

\section{Authors' Contributions}

All the authors participated in the writing of the manuscript. They all approve the final version of the manuscript.

\section{Ethics Authorisation}

The ethics committee's authorization was found prior to the start of the study.

\section{Conflicts of Interest}

The authors declare no conflicts of interest regarding the publication of this paper.

\section{References}

[1] Faye, A., Picaud, A., Ogwet-Igumu, N., Nlome-Nze, R.A. and Nicola, Ph. (1991) Eclampsia at the University Hospital of Libreville, 53 Cases for 41285 Deliveries from 1985 to 1989. French Journal of Obstetric Gynecology, 86, 503-510.

[2] Ahmadou, H. (2005) Epidemiology-Clinical Aspect of Eclampsia Management in the Reference Health Centre of the Commune V. Thesis Med., Bamako, 40.

[3] Cisse, C.T., Faye Dienne, M.E., Ngabo, D., Mbaye, M., Diagne, P.M. and Moreau, J.C. (2003) Therapeutic Indications and Prognosis of Eclampsia at the Dakar University Hospital. Journal de Gynécologie Obstétrique et Biologie de la Reproduction (Paris), 32, 239-245.

[4] Pambou, O., Ekoundzola, J.R., Malanda, J.P. and Buambos (1999) Management and Prognosis of Eclampsia at the University Hospital of Brazzaville in a Retrospective Study of 100 Cases. Black African Medicine, 36, 509.

[5] Dembele, N.F. (1995) Clinical Aspects of Eclampsia at Gabriel Touré Hospital about 65 Cases. Thesis Med., Bamako, 68.

[6] Diarra, I. (2005) Epidemiology-Clinical Aspects of Eclampsia in the Obstetric Gynecology Department of Gabriel Touré Hospital about 50 Cases. Thesis Med., Bamako, 70 .

[7] Mounier-Vehier, C., Amar, J., Boivin, J.-M., Denolle, T., Fauvel, J.-P., Plu-Bureau, G., et al. (2016) Hypertension and Pregnancy. Expert Consensus Statement from the French Society of Hypertension, an Affiliate of the French Society of Cardiology. La Presse Médicale, 45, 682-699. https://doi.org/10.1016/j.lpm.2016.05.012

[8] Merger, R., Levy, J. and Melchior, J. (1995) Vasculo-Renal Syndromes and Kidney Pathologies during Pregnancy. Precise Obstetrics 6th Masson Edition, Paris, 437.

[9] Beye, M.D., Diouf, E., Kane, O., Ndoye, M.D., Seydi, A., Ndiaye, P.I. and Sall, B.K. (2003) Management of Severe Eclampsia in Resuscitation in Tropical African Environments. About 28 Cases. French Annals of Anesthesia and Resuscitation, 22 
25-29. https://doi.org/10.1016/S0750-7658(02)00807-9

[10] Cissé, C.T., Ewagnignon, E., Hojeige, A. and Diadhiou, F. (1997) Eclampsia in the African Environment. Epidemiology and Prognosis at the Dakar University Hospital. Paris Hospital Seminar, 73, 1062-1067.

[11] Konate, S. (2008) Study of Eclampsia in the Gynecological-Obstetrics Department of the Chu of Point G. Thesis Med., 50.

[12] Fofana, B. (2008) Epidemiology-Clinical and Therapeutic Study of Eclampsia at the Fousseyni DAOU Hospital in Kayes. Mèd. Thesis, 45.

[13] Diakite, M. (2008) Maternal-Fetal Prognosis of Eclampsia the Gynecological-Obstetrics Department of the Gabriel TOURE University Hospital. Mèd. Thesis, 75.

[14] Miguil, M., Salami, S., Mouhaoui, M. and El Youssoufi, S. (2003) Epidemiological and Prognostic Aspects of Eclampsia in the Resuscitation Department of the Maternity Hospital of the Ibn Rochd University Hospital in Casablanca. Anesthesia Review, Paris, 177-180.

[15] Ferchiou, M., Sghaier, S., Zhioua, F., Hafsia, S., Akremi, A., Chennoufi, B. and Mariah, S. (1995) Eclampsia: An Obstetric Emergency Still Relevant Today. Maghreb Medecine, 293.

[16] Dumont, A., De Bernis, L., Bouvier Coll, M.H., Breart, G. and the MOMA Group (2001) Estimated Rate of Caesarean Section for Maternal Indications in a Population of Pregnant Women in West Africa (MOMA Survey). Journal of Obstetric Gynecology and Reproductive Biology, 31, 107-112.

[17] Traore, B., Thera, T.A., Beye, S.A., Mounkoro, N., Teguete, I. and Dolo, A. (2010) Maternal Mortality in the Gynecology and Obstetrics Department of the Ségou Regional Hospital in Mali. Retrospective Study of 138 Cases. Mali Medical, 25, 42-45.

[18] Videhoun, S.H. (2007) Study of Eclampsia in the Department of Multipurpose Resuscitation Anesthesia at the G-Point University Hospital. Med. Thesis, Bamako, 35, 82.

[19] Cisse, C.T., Ewagnignon, E., Hojeige, A. and Diadhiou, F. (1997) Eclampsia in African Environment: Epidemiology and Prognosis at the Dakar University Hospital. Paris Hospital Seminar, 73, 33-34, 1062-1067.

[20] N'diaye, F. (1979) Prematurity in Obstetric Environment Bamakois, Etiological Factors, Consequences, Prevention at the National Hospital of Point G. Thesis Med., Bamako, 22.

[21] Sanogo, A. (2001) High Blood Pressure and Pregnancy. Thesis Med., Bamako, 86, 44. 


\section{Investigation Sheet}

\section{Identification of the Patient}

Q1. Entry date:

Q2. File number:

Q3. Name and first name:

Q4. Age:

Q5. Place of residence:

Q6. Ethnie:

Q7. Marital status:

1) Bride; 2) Single; 3) Divorced; 4) Widow

Q8. Occupation:

1) Housewife; 2) Official; 3) Student; 4) Trader; 5) Others

Q9. Level of Education:

1) Illiterate; 2) Primary level; 3) secondary level; 4) Higher level Q10) Provenance:

1) Home; 2) C S C O M; 3) Private firm; 4) Reference Centre.

\section{Admission}

Q11. Admission mode:

1) Addressed by the family; 2) Evacuated; 3) Referred

Q12. Reason for evacuation:

1) Convulsion; 2) Loss of consciousness; 3) H T A; 4) Others

Q13. Moment of crisis occurrence

1) Anté-Anté-partum; 2) Per-partum; 3) Postpartum.

\section{Personal Antecedents}

Q14. ATCD Medical:

1) HTA; 2) Heart disease; 3) Diabetes; 4) Eclampsia;

5) Sickerpanocytosis; 6) Others

Q15. ATCD surgical:

1) Caesarean; 2) Uterine rupture; 3) Salpingectomy; 4) Others

Q16. ATCD obstetrics:

1) Gestity; 2) Parity; 3) Live child; 4) False layer; 5) IIG

Q17. Family ATCD:

1) HTA; 2) Heart disease; 3) Diabetes; 4) Eclampsia; 5) Other

Q18. Pregnancy term:

Q19. Prenatal consultation:

1) Yes; 2) No

If so specify the number.

Staff quality: 1) Matron; 2) Midwife; 3) Doctor; 4) Gynecologists; 5) Others.

\section{Exam at Admission}

Q20. General state: 
1) Preserved; 2) Passable; 3) Altered; 4) Glasgow

Q21. Consciousness:

1) Lucid; 2) Obsessed; 3) Deep Coma

Q22. Temperature:

Q23. TA:

Q24. OMI:

1) Present; 2) Absent; 3) Anasarque

Q25. Pulse

Q26. Diuresis Schedule:

Q27. Uterine contractions:

1) Yes, I do; 2) No

Q28. Uterine height:

Q29. BDCF:

1) Presents; 2) Absent. If present specify heart rate........

Q30. State of the pass:

1) closed; 2) open

If open specify its dilation in $\mathrm{cm}$

Q31. Ovular membranes:

1) Broken; 2) untouched

Q32. Amniotic fluid:

1) Claire; 2) Tinted

Q33. Presentation:

1) Cephalic; 2) Seat; 3) Cross/oblique

Q34. Commitment:

1) Engaged; 2) Unsigned

Q35. Basin:

1) Normal; 2) Limit; 3) Shrink

Q36. Additional reviews:
1) NFS
2) Uricemia
3) Creatininemia
4) Fasting Glycemia
5) 24-hour proteinuria

Q37. Treatment received before evacuation:

1) Anti-convulsive; 2) Anti-hypertensive; 3) 1/2; 4) Others

Q38. Medical treatment received at admission:

1) Anti-convulsive; 2) Anti-hypertensive; 3) 1/2;4) Sulfate of Magnesium

Q39. The anti-hypertensive used....

Q40. The anti-convulsant used.

Q41. Delivery route:

1) Caesarean; 2) Low track

Q42. If low lane, specify type

1) Natural; 2) Forceps; 3) Ventous 
Q43. Transfer to resuscitation:

1) Yes; 2) No

If so; length of stay

Q44. Maternal complications:

1) Yes, I do; 2) No

If so; Specify.

Q45. Maternal vital prognosis:

1) Alive; 2) Died (specify the cause.

Q46. Length of hospitalization.

Q47. Obstetrical Prognosis

1) Favorable; 2) Unfavourable; 3) Others

\section{Information on the New-Ne}

Q48. Number of children:

Q49. Sex:

Q50. Apgar:

1) 1st minutes; 2) 5 th minutes.

Q51. State of newborn at birth:

1) Eutrophic; 2) Premature; 3) Hypotrophic; 4) Macrosome

Q52. Resuscitated:

1) Yes, I do. 2) Name

Q53. Referred to Paediatrics:

1) Yes; 2) No

If Yes motive...... Evolution time

Q54. Fetal Malformation

1) Yes; 2) No

If Yes specify the type:

Q55. Fetal vital prognosis:

1) Alive; 2) Deceased (precise cause:..................) 